\title{
Determination of the antioxidant activity and polyphenol content of different types of Rhus coriaria Linn (sumac) from different regions
}

\author{
N. Soleymani Majd, S. Coe, S. Thondre and H. Lightowler \\ Functional Food Centre, Department of Sport and Health Sciences, Oxford Brookes University, Gipsy Lane, \\ Headington, Oxford OX3 OBP
}

Rhus coriaria Linn (Sumac) is a spice that is used most notably in Iranian, Turkish and Middle Eastern foods for seasoning and flavouring ${ }^{(1,2)}$. Many herbs and spices such as sumac have been demonstrated to have health benefits including antioxidant and antidiabetic properties due to their high polyphenol content ${ }^{(3)}$.

The main objective of this study was to determine the antioxidant activity and polyphenol content of sumac from four different regions (Turkey, Palestine, Iran and the UK) in either fresh or dried commercial powder forms.

The fruits of fresh sumac were air-dried and then ground. Sumac, from different regions and in both forms, was extracted using water, acetone $(80 \%)$ and ethanol $(80 \%)$ solvents. The extracts were analysed for polyphenol content and antioxidant activity (Table 1) using the Folin-Ciocalteu reagent $(\mathrm{FCR})^{(4)}$ and the Ferric Ion-Reducing Antioxidant Power (FRAP) ${ }^{(5)}$ assay, respectively.

The results of this work indicate that Fresh Brown sumac was high in antioxidant activity and polyphenol content in all types of extractions (water, acetone $(80 \%)$ and ethanol $(80 \%)$ ) compared with all other sumac types (with the exception of Iranian Brown sumac extracted using ethanol $(80 \%))$. Acetone $(80 \%)$ was the most efficient solvent to show the polyphenol content of all the sumac samples. Fresh Red, Iranian Brown, Turkish sumac and Fresh Brown sumac could have potential health benefits due to the high polyphenol content and antioxidant activity.

Table 1. Polyphenol content (g GAE/g) and total antioxidant activity (mmol/L) of each type and form of sumac

\begin{tabular}{|c|c|c|c|c|c|c|c|c|}
\hline \multirow[b]{2}{*}{ Sumac Type } & \multirow[b]{2}{*}{ Test } & \multicolumn{2}{|l|}{ Water } & \multicolumn{2}{|c|}{ Acetone $(80 \%)$} & \multicolumn{2}{|c|}{ Ethanol $(80 \%)$} & \multirow[t]{2}{*}{$\mathrm{P}$-value } \\
\hline & & Mean & SD & Mean & SD & Mean & SD & \\
\hline \multirow[t]{2}{*}{ Turkish } & Polyphenol & 1387 & 42 & 3464 & 885 & 2449 & 550 & $<\cdot 000$ \\
\hline & FRAP & 3496 & 246 & 10401 & 2572 & 25195 & 7754 & $<\cdot 000$ \\
\hline \multirow{2}{*}{ Palestinian } & Polyphenol & 176 & 18 & 1665 & 108 & 485 & 274 & $<\cdot 000$ \\
\hline & FRAP & 762 & 106 & 4165 & 255 & 12857 & 2991 & $<\cdot 000$ \\
\hline \multirow[t]{2}{*}{ Iranian Red } & Polyphenol & 437 & 27 & 1821 & 134 & 436 & 215 & $<\cdot 000$ \\
\hline & FRAP & 1186 & 378 & 4334 & 750 & 9035 & 3518 & $<\cdot 000$ \\
\hline \multirow[t]{2}{*}{ Iranian Brown } & Polyphenol & 1813 & 92 & 5136 & 306 & 2708 & 606 & $<\cdot 000$ \\
\hline & FRAP & 9017 & 2662 & 13851 & 2112 & 27576 & 6268 & $<\cdot 000$ \\
\hline \multirow[t]{2}{*}{ Fresh Red } & Polyphenol & 1237 & 134 & 4450 & 697 & 2066 & 829 & $<.000^{*}$ \\
\hline & FRAP & 7253 & 3129 & 10755 & 1494 & 14394 & 5964 & $<.003$ \\
\hline \multirow[t]{2}{*}{ Fresh Brown } & Polyphenol & 2895 & 549 & 5384 & 712 & 3395 & 1395 & $<.001^{*}$ \\
\hline & FRAP & 14081 & 4992 & 14185 & 2144 & 27351 & 8618 & $<.000$ \\
\hline
\end{tabular}

Data was tested for normality using the Shapiro-Wilks test. Values are the mean of three independent experiments. A one-way ANOVA and Kruskal Wallis test were used to compare within and between samples. The results were significant at $p<0.05$ and $p<0 \cdot 01 *$ (Kruskal Wallis post-hoc tests for pairwise comparisons)

1. Nasar-Abbas SM \& Halkman AK (2004) Int J Food Microbiol 97, 63-69.

2. Ozcan M \& Haciseferogullari H (2004) Bulg. J. Plant Physiol 30, 74-84.

3. Abu-Reidah IM, Jamous RM \& Ali-Shtayeh MS (2014) Jordan J Biol Sci 7, 233-244.

4. Singleton VL \& Rossi JA (1965) Am J Enol Vitic 16, 144-158.

5. Benzie IF \& Strain JJ (1996) Anal Biochem 239, 70-76. 